University of Nebraska - Lincoln

DigitalCommons@University of Nebraska - Lincoln

1978

\title{
Interpreting the Results of Nesting Studies
}

Harvey W. Miller

USGS Northern Prairie Wildlife Research Center

Douglas H. Johnson

USGS Northern Prairie Wildlife Research Center, Douglas_H_Johnson@usgs.gov

Follow this and additional works at: https://digitalcommons.unl.edu/usgsnpwrc

Part of the Other International and Area Studies Commons

Miller, Harvey W. and Johnson, Douglas H., "Interpreting the Results of Nesting Studies" (1978). USGS Northern Prairie Wildlife Research Center. 210.

https://digitalcommons.unl.edu/usgsnpwrc/210

This Article is brought to you for free and open access by the US Geological Survey at DigitalCommons@University of Nebraska - Lincoln. It has been accepted for inclusion in USGS Northern Prairie Wildlife Research Center by an authorized administrator of DigitalCommons@University of Nebraska - Lincoln. 


\title{
INTERPRETING THE RESULTS OF NESTING STUDIES
}

\author{
HARVEY W. MILLER, Northern Prairie Wildlife Research Center, U.S. Fish and Wildlife Service, Jamestown, North Dakota \\ $58401^{1}$ \\ DOUGLAS H. JOHNSON, Northern Prairie Wildlife Research Center, U.S. Fish and Wildlife Service, Jamestown, North \\ Dakota 58401
}

\begin{abstract}
Nesting studies are used to assess the production of birds and to evaluate nesting habitats. Most such studies involve finding nests in a given area and subsequently determining the proportion that hatched. Unfortunately, the results are often biased by unrecognized differences in the probabilities of finding successful and unsuccessful nests. The observed hatch rates of 1,900 nests of blue-winged teal (Anas discors) are presented to illustrate the relationship of hatch rates to time remaining until the nests should hatch. The Mayfield method of correcting for these biases is illustrated. Other examples demonstrate the possible effects of sampling procedures on observed hatch rates and nest density.
\end{abstract}

J. WILDL. MANAGE. 42(3):471-476

Nesting studies are common in investigations of waterfowl and other birds. Most are undertaken to assess the production of breeding birds and to evaluate nesting habitats and the techniques of managing such habitats. The objectives are to determine hatch rates and density of nests in selected habitats. The procedures commonly used are searching selected areas to find nests and subsequently checking those nests to ascertain whether or not the eggs were hatched.

Unfortunately, the nests of most species are initiated over periods of at least several days during which some of the nests may be destroyed. If nests are destroyed, many females will renest 1 or more times; consequently, it is common to find newly initiated nests after others of the same species have hatched. Continuous searches over such prolonged periods generally are impractical; hence, most studies involve periodic searches. If some nests were missed because they were initiated and destroyed between searches, the observed nest density clearly would be biased downward. Less obviously, but more importantly, the observed nesting success would be biased

\footnotetext{
${ }^{1}$ Present address: U.S. Fish and Wildlife Service, 1978 South Garrison Street, Denver, Colorado 80227.
}

upward. We have restricted our discussion to these biases.

These potential biases, among several commonly occurring in nesting studies, were recognized previously by Hammond and Forward (1956) and Mayfield (1960, 1961). Mayfield (1961) elaborated the method of estimating nesting success from nests observed during all or any portion of the period between initiation and hatch. The method has not been widely adopted. Mayfield therefore published the method again $14 \mathrm{yr}$ later and noted correctly (Mayfield 1975:456) that "not every published report shows awareness of the problem." At least 2 other investigators (Townsend 1966, Reed 1975) acknowledged the problem in waterfowl studies; Townsend used Mayfield's method in his analysis.

Our purpose is to bring the potential biases associated with periodic searching to the attention of investigators who may consider undertaking nesting studies. Our studies will exemplify the magnitude of these biases. We will also illustrate how the inconsistency of the biases invalidates many comparisons commonly made within and among nesting studies. We will demonstrate Mayfield's method for obtaining better estimates of the success and density of nests. 
We hereby acknowledge the support and guidance of $\mathrm{H}$. K. Nelson, former Director, and W. R. Goforth, Director of the Northern Prairie Wildlife Research Center, in the studies which led to this paper. We are especially grateful for the use of the nest records provided by, and for the constructive comments of, H. F. Duebbert, K. F. Higgins, L. M. Kirsch, A. T. Klett, and J. T. Lokemoen. Our thanks to D. A. Davenport for assistance with computer programing, to C. W. Shaiffer for drafting the figures, and to H. F. Mayfield for reviewing an earlier draft of this report. Our special thanks to L. M. Cowardin for perceptive technical and editorial comments on the manuscript.

\section{METHODS}

The records we present were obtained from studies of duck nesting conducted in North and South Dakota during 196772. The study areas included upland habitats on public and private lands selected to provide a broad range of the habitat types and land uses available to nesting ducks.

Searches to locate nests were conducted 15 May-15 July and generally between 0700 and $1400 \mathrm{~h}$ when ducks, laying as well as incubating, were most likely to be at the nest. Most areas were searched from 2 to as many as 4 times at intervals of approximately 3 weeks. Most searches were made with cable-chain flushing devices as described by Higgins et al. (1969), although a "Varty Drag" (Martz 1967:240) was used on some roadsides and a rope drag (Earl 1950:336) was used in some croplands. These methods of finding nests depended upon flushing the ducks; therefore, nests were not detected if they were not attended at the time of the search or if the duck did not flush (Higgins et al. 1969).
The site from which a duck flushed was examined, and if at least 1 egg was present, it was considered a nest. The number of eggs and stage of development (Weller 1956) were recorded along with details of the nest site. A marker was placed near each nest and the nest was reexamined on or soon after the anticipated hatching date. Nests in which at least 1 egg hatched were classified as successful. A few nests in which development ceased after they were found were classified as abandoned. All other nests were destroyed, usually by predators.

We emphasize that these methods were designed solely to measure the proportion of successful nests among all nests in an area, including those from renesting efforts. The methods are not in themselves adequate to determine the proportion of successful females (productivity) if renesting occurs.

\section{RESULTS AND DISCUSSION}

We limit our discussion to 1,900 nests of blue-winged teal found during the studies and classified both by stage of development when found and by fate as either hatched or destroyed (Table 1). Abandoned nests were excluded from analysis. Thirteen nests had hatched (ducklings were in the nest) when found, and the remainder were almost equally divided between the laying (934) and incubation (953) stages. The observed hatch rate of all nests (a common product of nesting studies) was 0.441 .

In studies reported here, the nests were examined on or soon after the anticipated hatching date; thus, the maximum possible exposure was the number of days between finding and hatching. We observed that blue-winged teal generally laid an egg each day, that there was an average of 10.2 eggs in the nests being 
incubated when found, and that the eggs were hatched typically on the 24th or 25th day of incubation. Therefore, we used an average of 35 days from initiation of the nest to hatching and calculated that, for example, a nest found with 4 unincubated eggs would hatch 31 days hence. When observed, the actual hatching dates corresponded closely with those calculated in this manner.

The data in Table 1 display a strong inverse relationship between observed hatch rates and the period remaining until the nests are due to hatch. The hatch rate, for example, of nests for which the period till hatch was 8 days (0.795) was nearly double that of nests for which the period till hatch was 16 days $(0.471)$. To be successful, nests must survive the combined laying and incubation periods. The hatch rate $(0.237)$ of 1 -egg nests, which had 34 days to go before hatching, would suggest that if all nests had been found when they were initiated (35 days to go), somewhat less than 24 percent of them would have hatched.

The data in Table 1 also demonstrate that the greater the proportion of nests found in the later stages of development, the more the composite hatch rate will be biased upwards. Conversely, nesting density will be biased further downward as the proportion of unsuccessful nests not found increases.

Mayfield (1961) recognized the improbability of finding a reasonably large sample of nests at the time they were initiated. Therefore, instead of lifetime survival rates, he measured daily survival rates during the periods he was able to observe the nests. For this, he considered each day that a nest existed to be 1 nestday of exposure. For example, a nest found on 10 May and still existing on 18 May would have survived 8 nest-days. If the nest had been destroyed, he assumed
Table 1. Observed hatch rates of blue-winged teal nests found in North and South Dakota, 1967-1972.

\begin{tabular}{|c|c|c|c|c|}
\hline \multirow{2}{*}{$\begin{array}{l}\text { Stage } \\
\text { when } \\
\text { found }\end{array}$} & \multirow{2}{*}{$\begin{array}{c}\text { Days } \\
\text { until } \\
\text { hatch }\end{array}$} & \multicolumn{2}{|c|}{ Number of nests } & \multirow{2}{*}{$\begin{array}{c}\text { Hatch } \\
\text { rate }\end{array}$} \\
\hline & & Hatched & Destroyed & \\
\hline \multicolumn{5}{|l|}{ Laying } \\
\hline $1 \mathrm{egg}$ & 34 & 9 & 29 & 0.237 \\
\hline 2 eggs & 33 & 9 & 23 & 0.281 \\
\hline 3 eggs & 32 & 9 & 29 & 0.237 \\
\hline 4 eggs & 31 & 9 & 37 & 0.196 \\
\hline 5 eggs & 30 & 27 & 57 & 0.321 \\
\hline 6 eggs & 29 & 23 & 75 & 0.235 \\
\hline 7 eggs & 28 & 29 & 79 & 0.269 \\
\hline 8 eggs & 27 & 26 & 93 & 0.218 \\
\hline 9 eggs & 26 & 34 & 76 & 0.309 \\
\hline 10 eggs & 25 & 40 & 87 & 0.315 \\
\hline $10+$ eggs & 24 & 53 & 81 & 0.396 \\
\hline \multicolumn{5}{|l|}{ Incubating } \\
\hline 4 days & 20 & 120 & 166 & 0.420 \\
\hline 8 days & 16 & 128 & 144 & 0.471 \\
\hline 12 days & 12 & 57 & 33 & 0.633 \\
\hline 16 days & 8 & 93 & 24 & 0.795 \\
\hline 20 days & 4 & 111 & 27 & 0.804 \\
\hline 22 days & 2 & 28 & 2 & 0.933 \\
\hline Pipped & 1 & 19 & 1 & 0.950 \\
\hline Hatched & 0 & 13 & 0 & 1.000 \\
\hline Total & & 837 & 1,063 & 0.441 \\
\hline
\end{tabular}

it had survived until midway through the period, an exposure of 4 nest-days. The number of nests destroyed divided by the total exposure of both surviving and destroyed nests would be the estimated daily mortality rate. That rate subtracted from 1.0 (which represents perfect survival) would be the daily survival rate which could then be projected to the lifetime of the nests studied as the expected nest hatch rate.

We calculated the expected hatch rate for 1-egg nests (Table 1) by Mayfield's method as he described. The resulting rate, 0.277 , appeared somewhat inconsistent with the observed rate of 0.237 (for a 34-day period). This inconsistency and other evidence suggested that the assumption that destroyed nests had survived until midway through the exposure period was incorrect, a possibility that Mayfield recognized but did not believe 


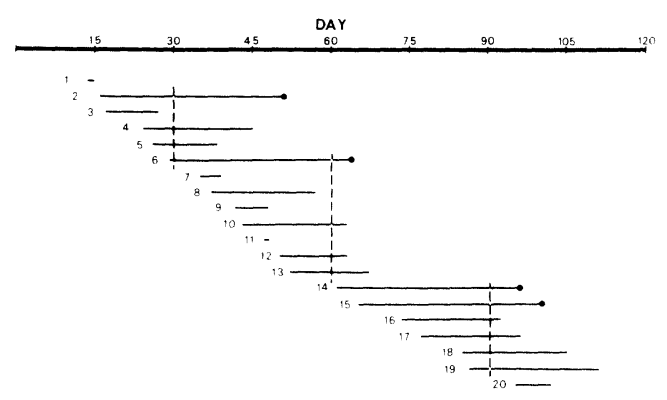

Fig. 1. Hypothetical survival times of a population of 20 nests initiated during a 120-day breeding season. Nests that hatch (survive 35 days) are indicated by a survival line ending with a dot $(\cdot)$. The results of searches for nests on days 30,60 , and 90 are also shown.

significant in the relatively short exposure periods of his studies. We calculated the expected survival of a nest that did not ultimately hatch, and found it to be much closer to 40 percent of the exposure period, rather than to 50 percent of the period.

The calculation of the hatch rate represented by the data in Table 1 will illustrate Mayfield's method. The exposure of nests that hatched is determined: $9 \times 34+9 \times 33+9 \times 32+\ldots+19 \times$ $1=13,712$ nest-days. Likewise, the exposure of nests that were destroyed is determined: $(29 \times 34+23 \times 33+29 \times$ $32 \ldots+1 \times 1=24,848) \times 0.40$ (to account for the portion of the possible exposure period the nests had survived) = 9,939 nest-days. The number of destroyed nests $(1,063)$ divided by the total exposure $(23,651$ nest-days) equals the daily mortality rate $(0.045)$ which, when subtracted from 1.0, yields a daily survival rate of 0.955 . The probability that a nest would survive from initiation to hatching is the daily survival rate over the 35-day lifetime or $0.955^{35}=0.200$.

A 20 percent expected hatch rate is consistent with that suggested by the 1-egg nests. We emphasize the great difference between this rate and the com- posite hatch rate $(0.441)$ which is ordinarily reported; the observed rate is 220 percent of the value estimated by the Mayfield method.

An improved estimate of nest density is also possible. The number of successful nests (837) was, according to the Mayfield method, about 20 percent of those initiated. Therefore, the number found represented $4,185(837 \div 0.20)$ nests actually initiated.

The difference between the observed and true hatch rates reflects more or less the sampling procedures used to find the nests. This relationship is illustrated by the hypothetical but not unlikely histories of 20 nests (Fig. 1). Nest 1 was initiated on day 14 and was destroyed 1 day later, Nest 2 started on day 16 and hatched, etc. We assumed for the sake of the example that all nests active on the search date were discovered. Our first hypothetical search was on day 30 when 4 nests were found; 2 hatched resulting in an observed hatch rate of 50 percent. On day 60, again 4 nests were found; 1 hatched resulting in an observed hatch rate of 25 percent. On day 90, 6 nests were found; 2 hatched and the observed hatch rate would be 33 percent. Had we conducted all 3 searches, we would have found only 13 of the 20 nests (Nest 6 would have been found on both day 30 and day 60) and observed a hatch rate of 31 percent. Actually, 4 of our 20 hypothetical nests hatched and the true hatch rate was only 20 percent. Obviously neither a single search nor 3 searches were adequate in this example. Even if searching had been at weekly intervals, some short-lived nests would have been missed. Because unsuccessful nests were less likely to be found, the observed hatch rate was consistently too high and the density too low.

Furthermore, differences in sampling 
Table 2. Hypothetical hatch rates of nests in 2 fields subjected to different treatments.

\begin{tabular}{|c|c|c|c|c|c|c|c|}
\hline \multirow[b]{3}{*}{ Fate } & \multicolumn{6}{|c|}{ Stage of development } & \multirow[b]{3}{*}{ Total } \\
\hline & \multirow[b]{2}{*}{ Laying } & \multicolumn{5}{|c|}{ Incubation (days) } & \\
\hline & & 4 & 8 & 12 & 16 & 20 & \\
\hline \multicolumn{8}{|c|}{ Treatment A } \\
\hline Hatch & 16 & 20 & 24 & 7 & 8 & 9 & 84 \\
\hline Fail & 24 & 20 & 16 & 3 & 2 & 1 & 66 \\
\hline $\begin{array}{l}\text { Hatch rate } \\
(\%)\end{array}$ & 40 & 50 & 60 & 70 & 80 & 90 & 56 \\
\hline \multicolumn{8}{|c|}{ Treatment B } \\
\hline Hatch & 3 & 4 & 5 & 24 & 28 & 32 & 96 \\
\hline Fail & 7 & 6 & 5 & 16 & 12 & 8 & 54 \\
\hline $\begin{array}{l}\text { Hatch rate } \\
(\%)\end{array}$ & 30 & 40 & 50 & 60 & 70 & 80 & 64 \\
\hline
\end{tabular}

procedures also could preclude valid comparisons of hatch rates and nest densities between areas. This can best be illustrated by hypothetical data (Table 2) representing the success of nests found in 2 fields subjected to Treatments $\mathrm{A}$ and B. Although all nests regardless of age are grouped in most studies, we have grouped these by stages of development to illustrate better the problems. Under Treatment A, arbitrarily assigned hatch rates were 40 percent for nests found in the laying stage, 50 percent for nests found 4 days along, etc., up to 90 percent for nests 20 days into incubation. The composite rate for all nests found was 56 percent. Under Treatment $\mathrm{B}$, hatch rates were a uniform 10 percent lower at each stage. Despite this difference, the composite rate was 64 percent, higher than Treatment A. These strange results simply reflect the majority of nests having been found in early stages of development in Treatment $\mathrm{A}$ and in later stages in Treatment B. This could be caused by more frequent searches in $\mathrm{A}$ with the result that most nests were found before they reached later stages of development.

The hypothetical data in Table 2 illustrate that the observed composite hatch

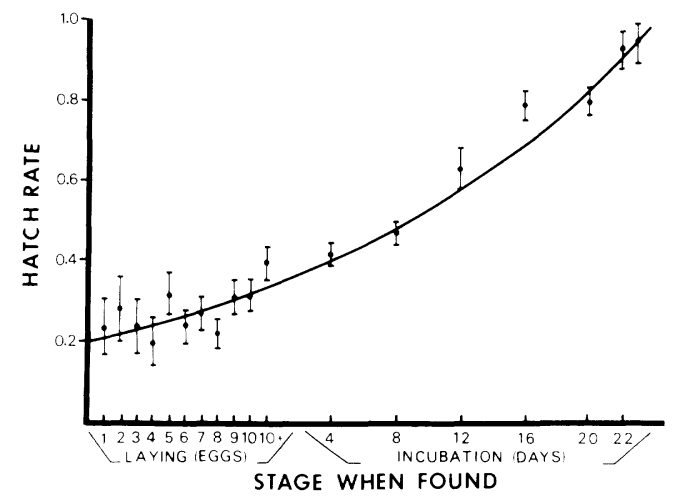

Fig. 2. Nest hatch rates according to stage when found $( \pm 1 \mathrm{SE})$ and estimated hatch rates determined from Mayfield method as described in text.

rates may be misleading. Under Treatment $\mathrm{B}$, for example, the hatch rate of "laying" nests, observed through most of their life span, is 30 percent, which suggests that the true hatch rate is not anywhere near 64 percent. Furthermore, comparison of the 2 treatments on the basis of the composite hatch rates would imply that Treatment B is better than Treatment A, a clearly erroneous conclusion. A misleading conclusion can be avoided if the hatch rates in each treatment are compared only within stage of development categories (laying, 4 days incubation, etc.), as displayed in Table 2. However, the Mayfield method enables all observations to be used in a simple comparison of the effects of the 2 treatments. If we assume that the total exposure period was 35 days and that all "laying" nests were found 30 days prior to hatching, we find the estimated hatch rates show Treatment A $(34 \%)$ to be clearly better than Treatment B (21\%).

An assumption in using Mayfield's method is that the daily survival rate of nests is constant among nests (Green 1977) and throughout the laying and incubation periods. We suspected some variation in the daily survival rates when, 
for example, the female started incubation and first occupied the nest overnight. There was, however, no important difference between the estimated survival rates of nests (Table 1) found during laying (daily survival rate $=0.9548$ ) and those found during incubation (daily survival rate $=0.9555$ ). Additionally, no consistent deviation was noted between expected and observed hatch rates (Fig. 2).

We have demonstrated the probable biases intermittent searches cause in the results of a nesting study. Pooling nests found at different stages of development resulted in an observed hatch rate biased upward and an observed density biased downward. These biases varied according to the procedures used to obtain the sample of nests and the results from pooled data could lead to erroneous conclusions. We have illustrated a simple procedure, the Mayfield method, of correcting for such biases and avoiding possibly erroneous conclusions. The corrected results obtained in our examples appeared to be consistent with our observations of blue-winged teal nests throughout the laying and incubation period. We therefore recommend the use of Mayfield's or similar methods of correct- ing the observed nesting success and density in future analyses.

\section{LITERATURE CITED}

EARL, J. P. 1950. Production of mallards on irrigated land in the Sacramento Valley, California. J. Wildl. Manage. 14(3):332-342.

GREEN, R. F. 1977. Do more birds produce fewer young? A comment on Mayfield's measure of nest success. Wilson Bull. 89(1):173-175.

HAMmOND, M. C., AND W. R. Forward. 1956. Experiments on causes of duck nest predation. J. Wildl. Manage. 20(3):243-247.

Higgins, K. F., L. M. KIrSCH, AND I. J. BALl, JR. 1969. A cable-chain device for locating duck nests. J. Wildl. Manage. 33(4):1009-1011.

MARTZ, G. F. 1967. Effects of nesting cover removal on breeding puddle ducks. J. Wildl. Manage. 31(2):236-247.

MAYFIELD, H. 1960. The Kirtland's Warbler. Cranbrook Institute of Science, Bloomfield Hills, Michigan. 242pp.

- 1961. Nesting success calculated from exposure. Wilson Bull. 73(3):255-261.

-1975. Suggestions for calculating nest success. Wilson Bull. 87(4):456-466.

REED, A. 1975. Reproductive output of black ducks in the St. Lawrence Estuary. J. Wildl. Manage. 39(2):243-255.

TownSEND, G. H. 1966. A study of waterfowl nesting on the Saskatchewan River Delta. Can. Field Nat. 80(2):74-88.

WELlER, M. W. 1956. A simple field candler for waterfowl eggs. J. Wildl. Manage. 20(2):111113.

Received 1 September 1977.

Accepted 20 February 1978. 